\title{
AN APPARATUS FOR THE PROLONGED ADMINISTRATION OF ARTIFICIAL RESPIRATION
}

\section{A Design for Adults and Children}

\author{
BY PHILIP DRINKER AND LOUIS A. SHAW
}

(From the Departments of Ventilation and Illumination and of Physiology, Harvard School of Public Health, Boston, Mass.)

(Received for publication December 17, 1928)

\section{INTRODUCTION}

Up to the present time, artificial respiration has generally been administered either $(a)$ by manual methods or $(b)$ by forcing air under pressure into and out of the lungs by means of an insufflating apparatus.

The first method was brought to its present state of development by Sir E. A. Sharpey Schäfer. The obvious defect in this method lies in the fact that the chest is never inflated; it is only deflated and then allowed to return to the normal position through its inherent elasticity. This process is in the reverse direction to that which is normal and if, for any reason, the tone of the respiratory muscles becomes impaired, the chest will refuse to return to the normal position, thereby creating a situation in which adequate ventilation is rendered impossible.

The second means of artificial respiration has reference to positive pressure devices such as the bellows (Keith, 1909) and to the lungmotor and pulmotor, which force air in and out of the lungs, usually through a face mask fitted with inlet and outlet valves. Among rescue squads in this country and Canada, this general method has been discredited and discarded (Engineering Committee of the Conference on Electric Shock, 1928).

A wholly new method has recently been devised by Thunberg (1927). The patient is placed in a chamber in which the pressures are alternately raised and lowered about $55 \mathrm{~mm}$. of mercury. Since the pressure changes are equal on both sides of the thoracic wall 
there is no movement of the chest. The alternate rarefaction and compression of a fixed volume of air causes a volume flow which is proportional to the changes in pressure and which thus produces adequate gas exchange in the lungs.

A fourth method was described by Doe (1889). This apparatus was devised for resuscitating asphyxiated children. It consisted of a small box, over an opening in which a rubber dam was stretched. The infant was so placed in the box that his nose and mouth were held against a hole in the rubber dam. Through a tube connected to the box a person outside alternately blew in and sucked out air. Although there is no reason to doubt the efficacy of such a method, the task of supplying the pressures in this way for long periods must have been arduous and the results rather uncertain.

In South Africa, Steuart (1918) suggested the use of a mechanically operated device for inducing artificial respiration in children with anterior poliomyelitis. To quote the author: "The principle used is to place the child's thorax and abdomen in a rigid air-tight chamber communicating with a large bellows, which periodically causes a partial vacuum in the box." Either positive or negative pressures, or both, were obtainable and could be regulated as to frequency and amount. Apparently the author carried his work no further (so far as the literature indicates) than the suggestion of this device.

Through newspaper reports, our attention was brought to a device patented (1928) by Eisenmenger of Vienna. We had an opportunity recently to make experiments with this apparatus on normal men and also to serve as subjects. A rigid leather dome-shaped piece lined with rubber is placed over the patient's chest, extended about over the region from the clavicle to the umbilicus, and strapped tightly in position. Alternate positive and negative pressures inside the dome are applied by an electrically driven diaphragm pump. Although the dome-shaped cover is not air-tight at any time, the pump produces any desired pressure up to about $400 \mathrm{~cm}$. of water, either positive or negative.

The apparatus which we have developed (figs. 1 and 2) is based on principles somewhat different from any of those mentioned. The patient's body is entirely enclosed in a cylindrical sheet-metal tank sealed at one end. At the other end is a flat lid, to which is attached 
a rubber collar. The patient's head and part of his neck protrude through the collar, the head lying upon an adjustable support outside the tank. Since the patient is thus enclosed in an air-tight chamber, the pressure around the body may be alternately raised and lowered while the head always remains at atmospheric pressure. When the

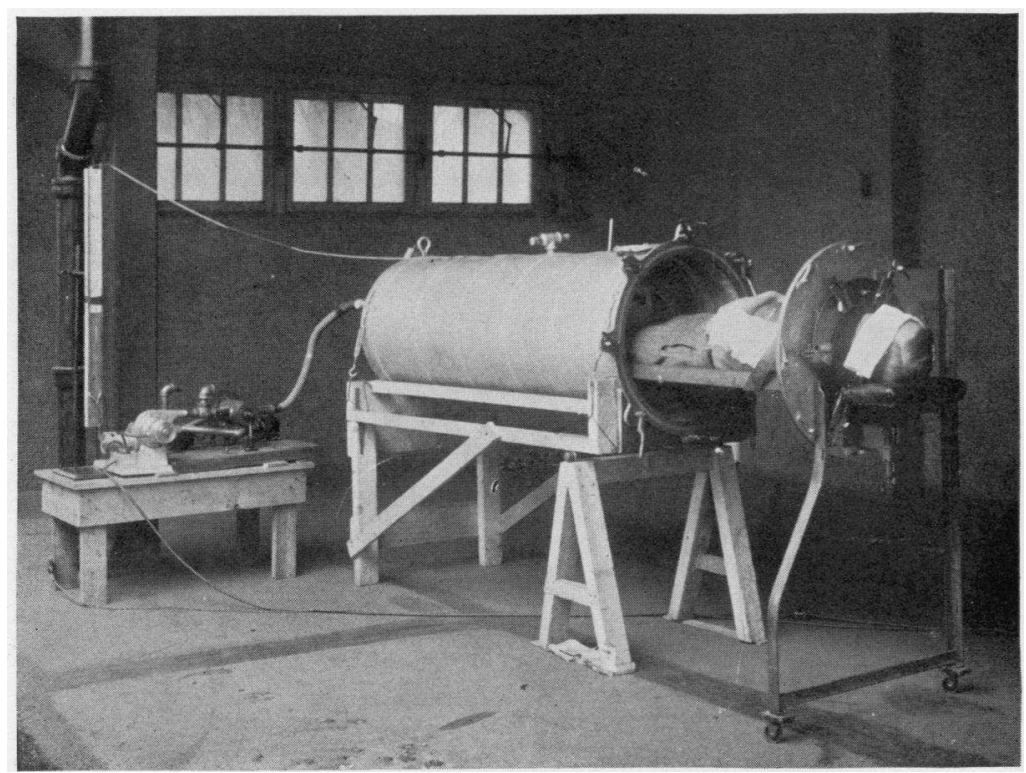

Fig. 1. Mechanical Respirator, Showing Tank with Pump Mechanism Connected by Flexible Tube at Foot End

The collar and head rest are in place and the patient is ready to be pushed into the tank.

pressure in the tank is lowered, the chest expands and air rushes into the lungs. When the pressure is raised, the chest is compressed and air is forced out of the lungs. By this method, movement of the chest is induced in such a manner as to simulate the natural respiratory movements.

\section{DESCRIPTION OF NEW MECHANICAL RESPIRATOR}

The body of the respirator is made of metal (preferably sheet iron) welded at all joints. Rails in the form of "channels" are welded to the 
inside. The patient lies on a mattress supported on an angle iron frame to which springs are hooked on all four sides. This bed frame is fastened rigidly to the lid of the tank, the bed and lid rolling in and out of the tank on wheels. The rubber collar through which the patient's head protrudes is fastened to the outside of the lid. The

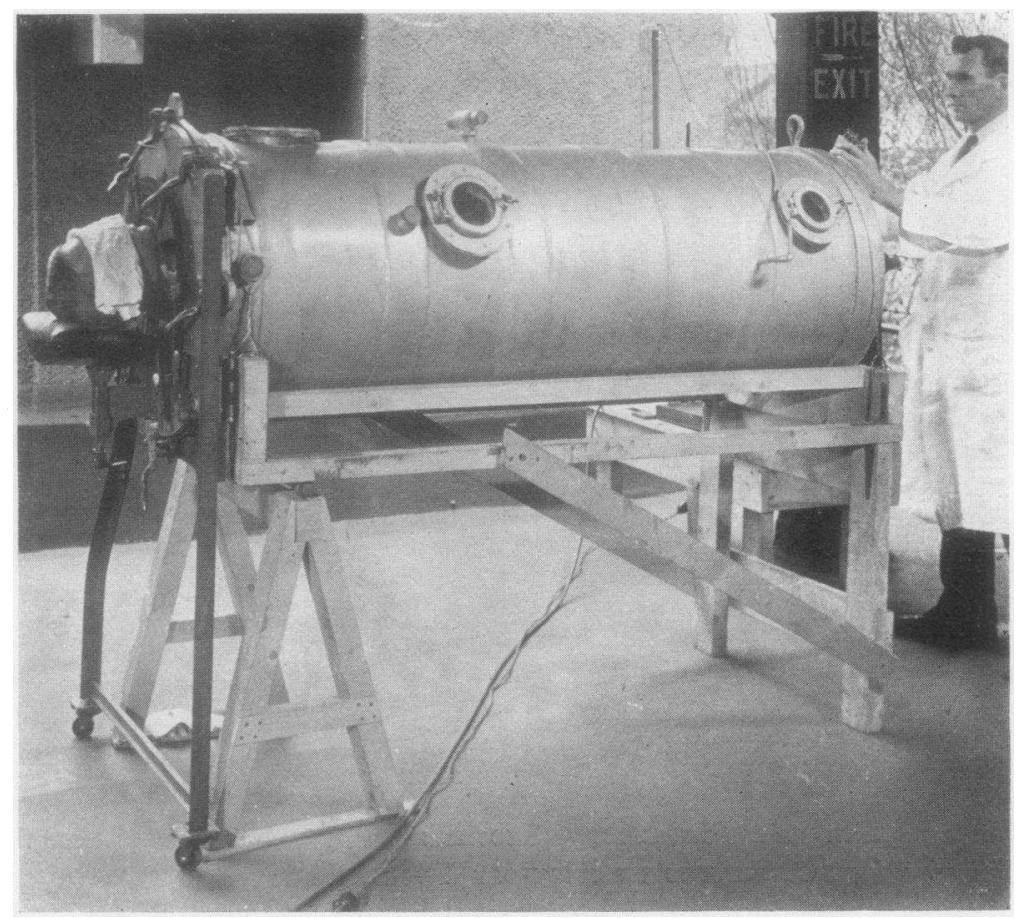

Fig. 2. A Patient in the Respirator

Note the position of the port-holes. Attendant has his hands on the dial of the thermostat which controls the temperature and humidity of the air in the tank.

patient can thus be taken out occasionally for examination without removal of this collar (fig. 3). To transfer a patient from a bed or stretcher to the tank requires about two minutes. If necessary, manual respiration can be carried on during this interval.

The lid of the tank is clamped tightly against the body of the tank by means of refrigerator locks. On the inner surface of the lid there is a small $\boldsymbol{\Lambda}$ - shaped rim, which fits into a seamless rubber gasket dove- 
tailed into the body of the tank. This arrangement assures a sufficiently tight seal on clamping the lid in place.

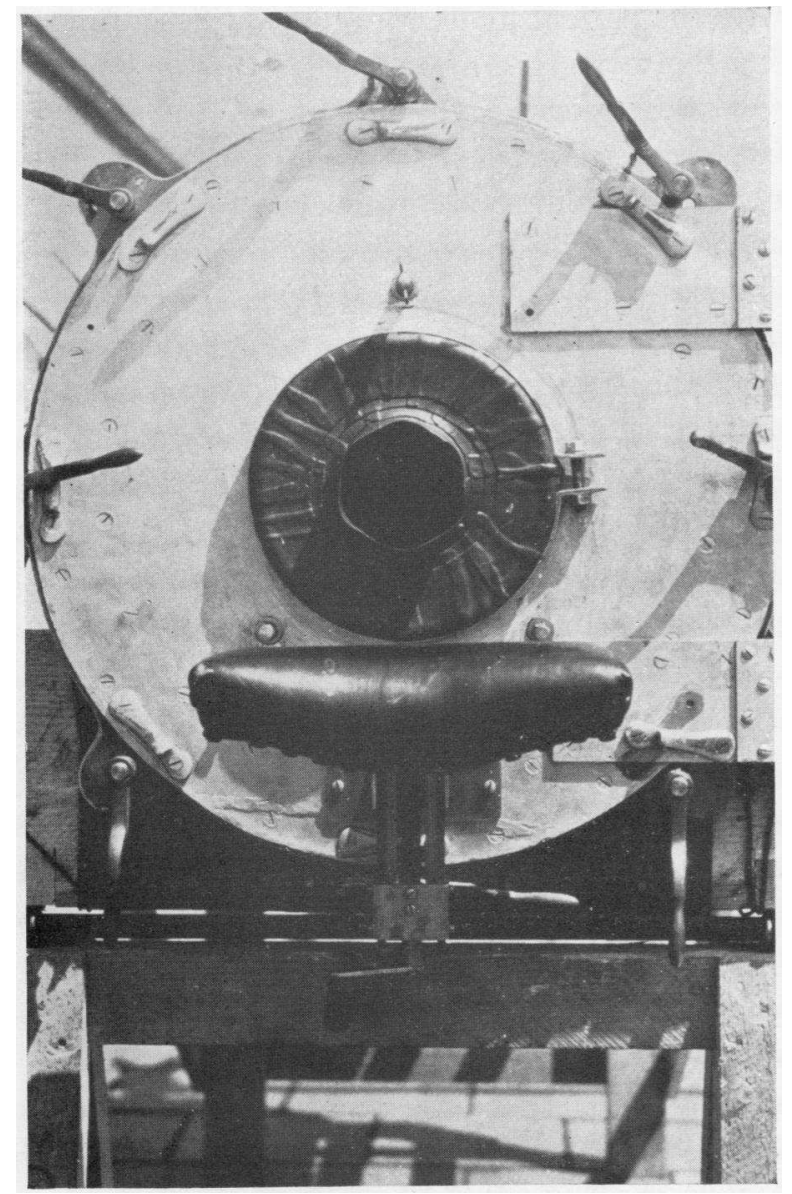

Fig. 3. Head End of Tank Showing Adjustable Head Rest and Rubber COLLAR

In future, the collars will be molded in a single piece and bolted to the lid of the tank by metal rings with wing nuts.

The tank can be rotated about 75 degrees in both directions and the foot end can be raised or lowered about 15 degrees with the horizontal. The chief purpose of these maneuvres is to give the patient a change in 
position. If necessary, sides can be placed on the bed to keep the patient in position when the tank is rotated.

The body of the tank is equipped with marine-type glass portholes for observing the patient and with numerous small holes (pipe taps) for inserting thermometers, attaching manometers, connecting pneumographs, blood pressure cuff, or stethescope. For taking x-ray photographs of chest movements, the glass of the porthole is replaced by a sheet of thin aluminium permeable to $\mathrm{x}$-rays.

The pumps (fig. 1) which produce the pressure consist of two small universal blowers. ${ }^{1}$ The valve mechanism controlling the pressure alternations is made up of two concentric cylinders; the outer one is stationary and the inner one driven by a worm gear connected through a variable speed motor. Holes are cut at certain intervals in both cylinders and these holes in turn lead out on one side to the pumps and on the other to the tank. The valves, driving gear, and cocks are so arranged that the pumps may be used in series, in parallel, or singly. Either pump may be disconnected and replaced by a new one without stopping the apparatus. Any combination of pressures, positive or negative, up to about $60 \mathrm{~cm}$. of water can be applied and any number of pressure changes (i.e., breaths) from 10 to 40 per minute are obtainable.

The manometer which indicates pressures within the tank is filled with water colored red for visibility; the scale measures in half centimeters above and below the zero point (atmospheric pressure). In controlling pressures, it is difficult to read both limbs of the manometer at the same time. We therefore use the rising limb only and, by measuring in half centimeters (thus doubling the actual reading) get the total excursion.

The rubber collar (fig. 3) was developed by the Hood Rubber Company. The diameter of the hole in the collar for the neck and of the hole in the lid of the tank through which the subject's head must pass and to which the collar is fixed were taken from figures supplied us by

${ }^{1}$ Manufactured by the Electric Blower Company, Boston, Mass. These blowers were chosen because they are designed for continuous service and deliver a considerable volume of air against 75 to $100 \mathrm{~cm}$. of water pressure. Although these pumps function satisfactorily, their noise is a drawback in hospital work. We expect shortly to substitute pumps of more silent operation. 
the Cluett Peabody Company, collar manufacturers, and by the Knox Hat Company. Dimensions for the smaller collar sizes were taken from our own measurements on infants and children.

Excessive movement of the rubber collar from the pressure changes is prevented by semi-lunar discs of thin metal placed on both sides of the collar. This permits the use of thin rubber about the neck. At present, we are using a series of six collar sizes, which seems adequately to cover variations in neck sizes from children two years of age to adults.

The rubber collars must withstand continuous pressure changes of from 0 to $60 \mathrm{~cm}$. of water without appreciable leakage; they must be actually air-tight at low pressures; and, at the same time, they must not be uncomfortable. Up to the present, all of our collars have been built by hand, but we hope soon to have them moulded in one piece, which would materially reduce their cost and increase their uniformity.

\section{PRESSURES REQUIRED TO INDUCE BREATHING}

Our chief purpose in making this apparatus was to secure a device for treating patients suffering from protracted cases of respiratory failure, such as are induced by severe carbon monoxide poisoning, electric shock, morphine poisoning, poliomyelitis, and the like. The important question of how much pressure is needed to induce breathing in pathologic cases was estimated by using a number of normal men and women as subjects and observing their reactions when the pumps were working against various pressures.

Table 1 gives the results of a series of experiments on normal men and women, chosen at random from the laboratory personnel in the building. The plot of these data (fig. 4) shows that there is a very considerable variation in individual reactions and experiments like nos. 11 and 12 indicate that the same subject does not necessarily react in the same way in two experiments under approximately the same pressures. As the normal minute volume itself varies as much as 10 or 20 per cent, it seems probable that the scattering of the points about the dotted line of figure 4 are within the normal expected variation.

In order to determine approximate threshold pressures on a normal subject, one observes the manometer and gradually increases the 
TABLE 1

Changes in minute volume resulting from various pressures

\begin{tabular}{|c|c|c|c|c|c|c|c|}
\hline $\begin{array}{l}\text { Experi- } \\
\text { ment }\end{array}$ & Subject & $\begin{array}{c}\text { Vital } \\
\text { capacity }\end{array}$ & $\begin{array}{l}\text { Normal } \\
\text { minute } \\
\text { volume }\end{array}$ & $\begin{array}{l}\text { Average } \\
\text { plus and } \\
\text { minus } \\
\text { pressures } \\
\text { applied }\end{array}$ & $\begin{array}{l}\text { Resulting } \\
\text { minute } \\
\text { volume }\end{array}$ & $\begin{array}{c}\text { Increase } \\
\text { above } \\
\text { normal }\end{array}$ & $\begin{array}{l}\text { Approximate } \\
\text { threshold pressure }\end{array}$ \\
\hline & & liters & liters & cm. water & liters & per cent & cm. water \\
\hline 1 & $A(m)$ & 6.1 & 10 & 7.6 & $8.4^{*}$ & -15.7 & 10 \\
\hline 2 & & & & 10.2 & $10.0^{*}$ & 0 & . \\
\hline 3 & & & & 12.0 & $12.6^{*}$ & 25.7 & \\
\hline 4 & & & & 19.0 & $16.3^{*}$ & 63.0 & \\
\hline 5 & & & & 21.0 & $23.5^{*}$ & 135.0 & \\
\hline 6 & & & & 30.7 & $40.0^{*}$ & 300.0 & \\
\hline 7 & B (m) & 5.8 & 5.8 & 4.3 & 5.5 & -5.0 & 10 \\
\hline 8 & & & & $9: 1$ & 5.8 & 0 & \\
\hline 9 & & & & 11.6 & $7.7^{*}$ & 33.0 & \\
\hline 10 & & & & 14.0 & 10.8 & 86.2 & \\
\hline 11 & & & & 21.3 & $11.6^{*}$ & 100.0 & \\
\hline 12 & & & & 21.6 & 17.2 & 193.0 & \\
\hline 13 & $C(\mathrm{~m})$ & 5.1 & 9 & 6.3 & 10.6 & 17.8 & 6 \\
\hline 14 & & & & 11.5 & 13.9 & 54.0 & \\
\hline 15 & & & & 19.1 & 19.0 & 111.0 & \\
\hline 16 & $\mathrm{D}(\mathrm{f})$ & 3.2 & 5 & 7.9 & 4.4 & -12.0 & 8 \\
\hline 17 & & & & 9.7 & $9.8^{*}$ & 96.0 & \\
\hline 18 & & & & 11.6 & 10.0 & 100.0 & \\
\hline 19 & & & & 17.1 & $14.8^{*}$ & 196.0 & \\
\hline 20 & & & & 21.5 & 22.2 & 340.0 & \\
\hline 21 & $E(m)$ & 4.5 & 8.2 & 8.2 & $15.4^{*}$ & 87.5 & 4 \\
\hline 22 & & & & 16.4 & $23.6^{*}$ & 188.0 & \\
\hline 23 & $F(m)$ & 5.6 & 8 & 5.0 & 11.6 & 45.0 & 2 noticeable \\
\hline 24 & & & & 9.5 & 16.2 & 100.0 & 20 complete \\
\hline 25 & & & & 15.1 & 19.6 & 145.0 & control \\
\hline 26 & & & & 20.3 & 34.7 & 334.0 & \\
\hline 27 & $G(f)$ & 2.4 & 6.6 & 6.8 & $12.7^{*}$ & 93.0 & 4 \\
\hline 28 & & & & 17.3 & $22.0^{*}$ & 233.0 & \\
\hline
\end{tabular}

* Minute volumes determined in the course of taking Benedict metabolism records. Other values determined spirometrically (Drinker, 1927). 
pressures-positive and negative-by turning the proper valves. When there is too little pressure to be effective, the subject's breathing is not in perfect synchronism with the alternations of the pump and the excursions of the water in the manometer are therefore very irregular.

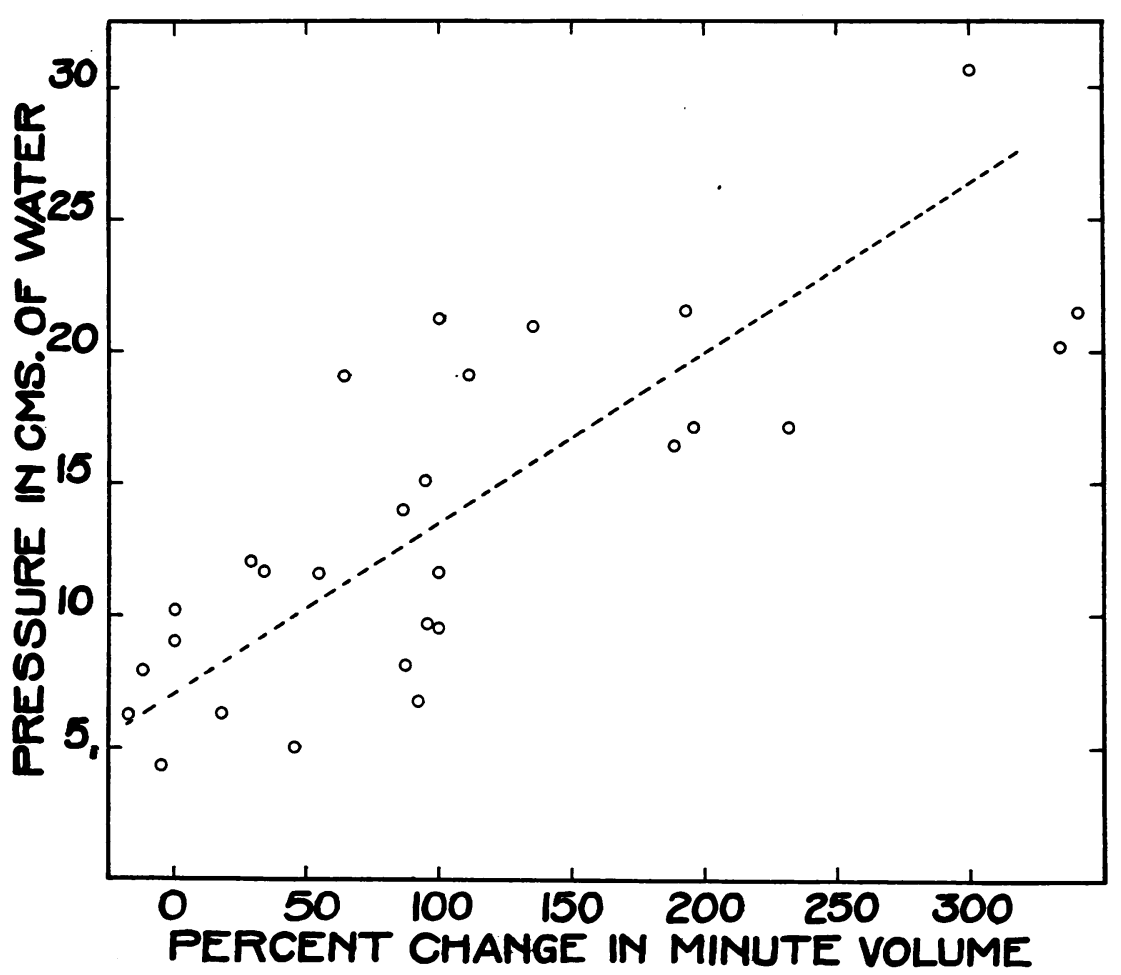

Fig. 4. The Data of Table 1 Plotted as a Means of Determining Approxmate Threshold Pressures-Pressures at Which the Respiratory Movements of the Average Subject fall into Perfect SynCHRONISM WITH THE PUMP

Where the dotted line passes through zero is the approximate threshold pressure

As the pressures are increased, a point is reached (generally at about 5 to $10 \mathrm{~cm}$.) when the subject falls into rhythm with the pump and remains so, no matter how much the pressure is increased subsequently. For one man of normal physique (subject F, table 1) about 
18 to $20 \mathrm{~cm}$. were required before the pump completely controlled his breathing. Another subject, A, a tall thin man, fell in at about $10 \mathrm{~cm}$. With refractory subjects like $F$, synchronism with the pump is generally achieved by starting with pressures of about 18 to $20 \mathrm{~cm}$. and then rapidly coming down to 5 to $10 \mathrm{~cm}$., which, from figure 4 , seems to give about the average threshold range.

The conditions encountered in the tank are quite unlike anything one experiences normally. The head is at atmospheric pressure and the chest, diaphragm, and abdomen are alternately under positive and negative pressures. Of the two, negative pressure (inducing inspiration) is much the more difficult to resist.

There is no certain way of predicting the optimum combination for any individual. The most satisfactory procedure seems to consist in having all the controls as flexible as possible and quickly exploring the likely pressure ranges until a reasonable one is found to fit the patient.

\section{THE EFFECT OF ALTERNATE POSITIVE AND NEGATIVE PRESSURES UPON SPEECH}

Another method of determining threshold pressures for normal subjects is given by the effect of pressure changes upon speech. A new subject-especially if he understands the apparatus - usually enters the tank with a certain degree of skepticism - he doubts the effectiveness of such small pressure changes. As the pressures are gradually increased, he is likely to attempt to talk or laugh and, as either function is cut off abruptly by inspiration, one can easily tell when the threshold pressure is approached. For the majority of subjects, speech is seriously hindered at pressures of about 5 to $10 \mathrm{~cm}$. and is almost wholly prevented at pressures of about $20 \mathrm{~cm}$. or more. This, of course, applies to the inspiration phase only.

PRESSURES EXERTED IN ARTIFICIAL RESPIRATION BY THE SCHÄFER METHOD

At our suggestion, Mr. T. J. Shaughnessy, supervisor of resuscitation and instruction in the Consolidated Gas Company of New York, was so good as to have his rescue squads, numbering altogether about 45 
men, perform the Schäfer prone pressure method on the platform of a spring scale which registered the pressure in pounds applied by the operator. All the subjects had repeatedly used the Schäfer method in actual resuscitation work in and about New York City. The results of the experiment, plotted in figure 5, show that the pressures applied ranged from about 41 to 63 kilos and varied roughly with the weight of the operator.

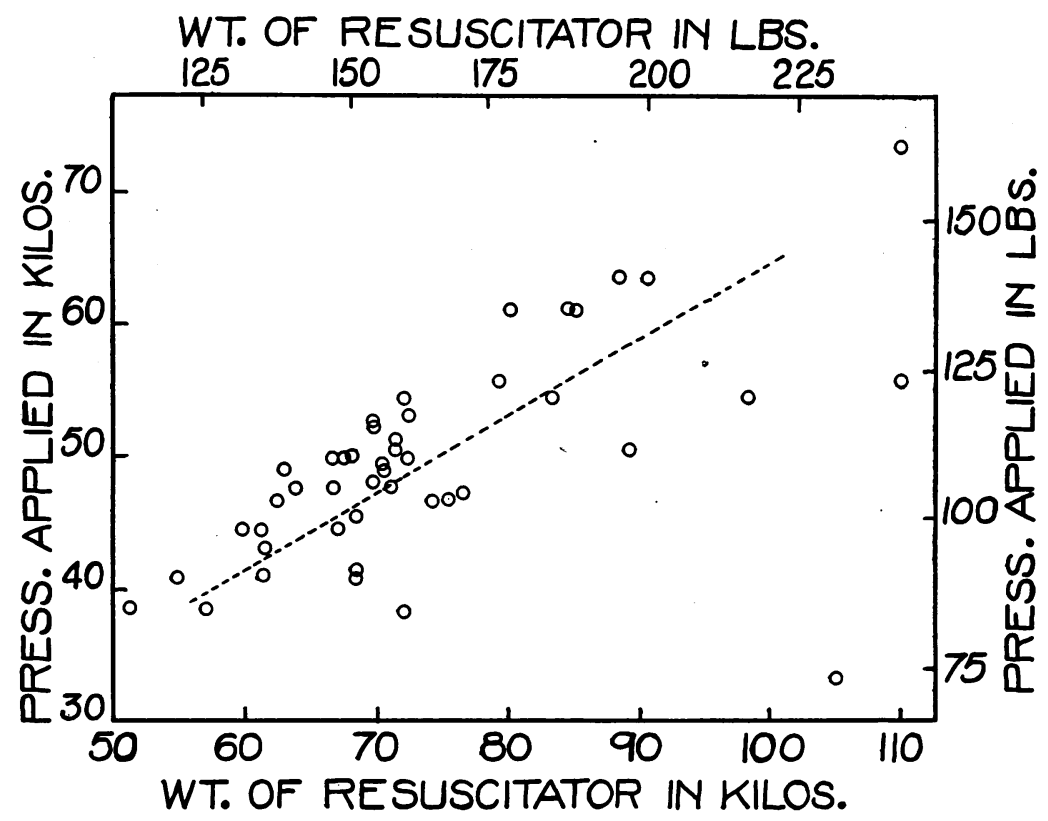

Fig. 5. A Comparison of the Weights and Pressures Applied by 45 Experienced "Prone Pressure Resuscitators" from the Resuscttation

Crews of the Consolidated Gas Conpany of New York

Courtesy of Mr. T. J. Shaughnessy

This range is somewhat above the 23 to $41 \mathrm{kgm}$. (50 to 90 pounds) given by Keith (1909) as practical working figures in applying the Shäfer method.

Mr. Shaughnessy's data are of interest to us because they show what relatively great pressures must be applied over a small area (the palms of two hands) in practical resuscitation work. In this case, of course, positive pressure only (forcing expiration) is exerted. 


\section{THE EFFECT OF THE RESPIRATOR ON METABOLISM}

If a subject is passive and readily falls into rhythm with the pump, it is reasonable to expect a consequent reduction in metabolism, for the normal muscular work of breathing is supposedly being performed in large part by the pump. A considerable series of careful experiments upon normal men and women did not, however, bear out this expectation. The results showed that, for the most part, metabolism was not affected significantly unless threshold pressures were considerably exceeded; then increases of 10 to 20 per cent were obtained, owing, apparently, to the muscular work of resisting over-ventilation.

\section{OVER-VENTILATION AND ITS SIGNIFICANCE}

It is impossible to produce on a normal subject more than a slight degree of apnea by the Schäfer method. This method also has little effect upon a subject who has previously breathed forcibly for some minutes and has already become apneic. The mechanical respirator, on the other hand, offers a convenient method for producing apnea, for forcing a resistant or apneic subject to breathe, and for studying recovery from apnea.

Figure 6 shows a Benedict metabolism record of subject $\mathrm{A}$ in the tank. He first breathed normally, then with one pump running at 20 $\mathrm{cm}$. pressure, then with two pumps at about $30.7 \mathrm{~cm}$. The record shows the subsequent apnea which extended over a period of some four minutes. There was, clearly enough, an appreciable consumption of oxygen during these four minutes, although the respiratory movements were negligible.

In making this particular record, the rubber flap valves ordinarily used in the Benedict apparatus to control inspiration and expiration were removed. Instead" we used a small blower or "impeller" devised by Collins for use with the apparatus when the subject is breathing deeply, as in performing muscular work. In this way, oxygen at atmospheric pressure is brought continually to the subject, so that, as the oxygen in the lungs is converted into carbon dioxide, more oxygen is drawn in to replace it. This process can take place with no visible chest movement.

It may well be objected that the data obtained upon healthy sub- 


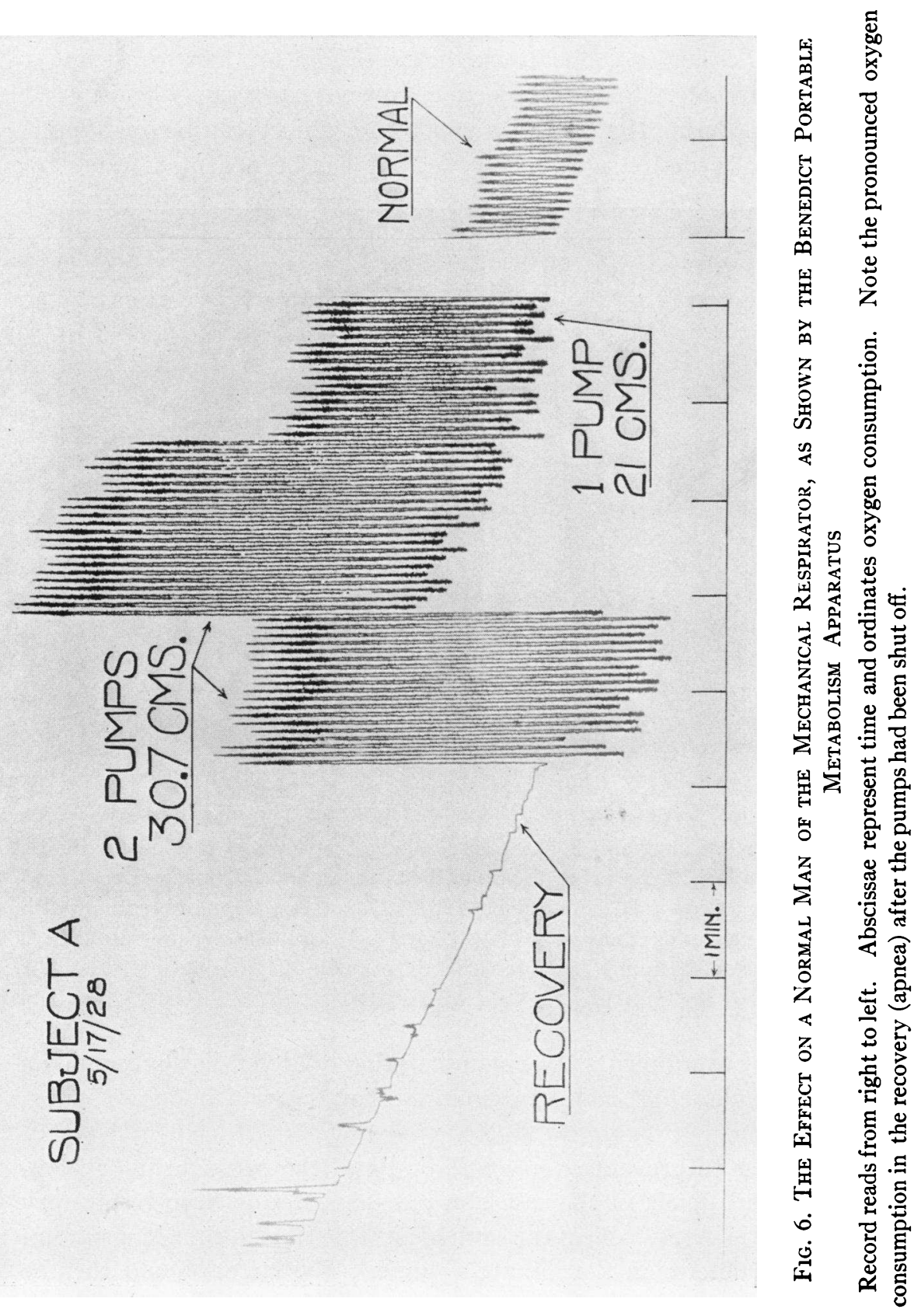


jects are not valid and may only reflect the fact that our subjects (table 1) find it easier to coöperate with the respirator than to assume a passive attitude. Such an objection, however, may safely be disposed of by considering the ease with which the subject can be over-ventilated to any desired degree (fig. 6). It has been demonstrated by

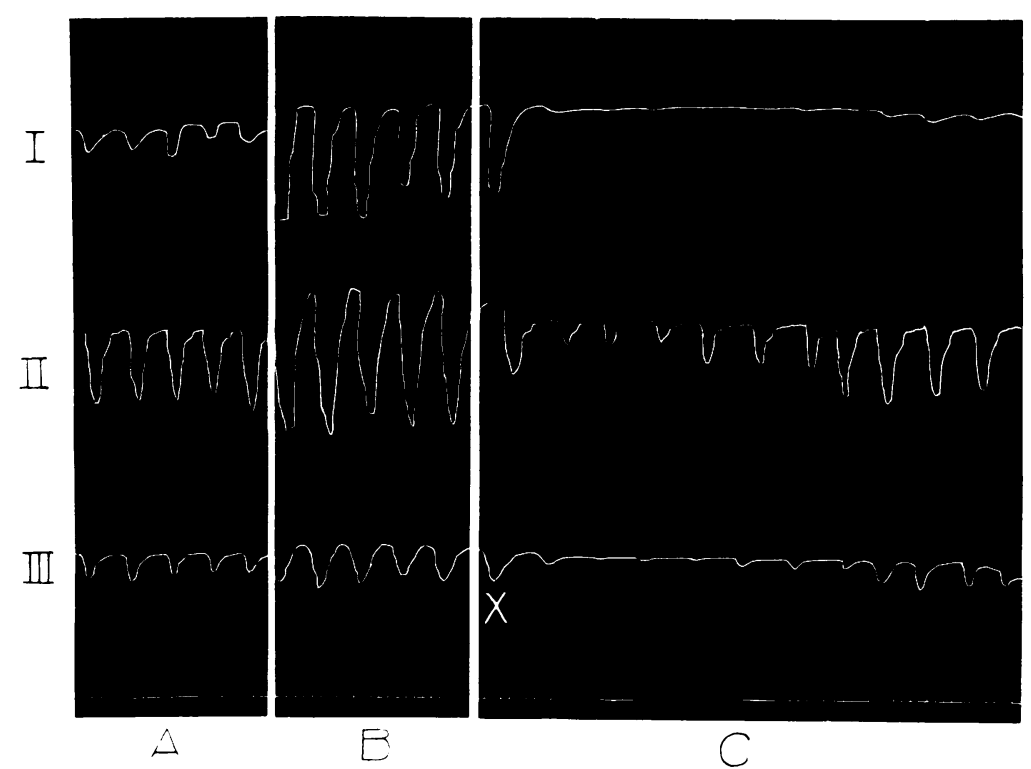

Fig. 7. P'xemociraphic Records Thkfi ox Normal Subject

I, Porter pneumograph is placed around chest at level of the fourth rib; II, pneumograph is $2.5 \mathrm{~cm}$. below the tip of the xyphoid; and III, pneumograph is 1.3 $\mathrm{cm}$. below position in II. $A$ represents normal breathing, $B$ forced breathing with the pump delivering an average of +12 and $-10 \mathrm{~cm}$. of water pressure, and $C$ recovery after the pump had been shut off at point $X$. Time intervals $=-1$ second.

laboratory experiments upon mammals that over-ventilation is resisted by a muscular effort no less pronounced than that which follows underventilation.

In order to prevent over-ventilation and the consequent development of alkalemia in the case of a patient suffering from respiratory failure, it is best to collect the expired air from time to time in a spirometer and determine the minute volume. The latter should then be 
regulated to conform with the average respiratory volume per minute per kilogram of body weight for the particular individual.

\section{CHEST AND DIAPHRAGMATIC MOVEMENTS}

\section{Pneumograph records}

In order to study the relative movement of the chest and diaphragm in natural and in mechanically forced breathing, three Porter pneumographs were placed on subject $A$, connected so as to write separate records on a kymograph equipped with a second marker.

The first pneumograph, I, was placed at the level of the fourth rib, the second, II, $2.5 \mathrm{~cm}$. below the tip of the xyphoid, and the third, III, $13 \mathrm{~cm}$. below the second. A record of normal breathing was then made (fig. 7, $A$ ) with the subject lying at rest in the tank. Next the pump was run at pressures of +12 and $-10 \mathrm{~cm}$. giving the record shown in figure $7, B$. Finally, the pump was stopped and the period of recovery from the slight apnea produced is shown in figure $7, \dot{C}$.

Compared with normal breathing, breathing induced by the mechanical respirator showed a marked increase in chest movement, particularly in movement of the upper part of the chest. Directly after the pump was stopped, there appeared to be practically no movement in the first and third pneumographs and a slight movement in the second. As recovery progressed, diaphragmatic breathing (the third pneumograph) became more pronounced and, after about one minute, was practically normal. The upper pneumograph shows that normal breathing had not been resumed about one minute after the pump was stopped.

\section{$X$-ray record}

A portable $x$-ray machine was arranged so that the tube was directly over the central porthole, near the head end of the tank (fig. 2). By replacing the glass of the port with thin aluminium, $x$-ray photographs of the subject's chest movements could be taken. The subject in this case was an athletic man 27 years of age, apparently in excellent health. His vital capacity was 4.5 liters.

Dr. Merrill C. Sosman ${ }^{2}$ was kind enough to take the pictures for us and commented upon the resulting plates as follows:

${ }^{2}$ Roentgenologist-in-chief, Peter Bent Brigham Hospital, Boston. 
Films of the chest on deep voluntary inspiration and expiration show a maximum movement of the diaphragms $8.8 \mathrm{~cm}$., with a change in diameter of the chest of $3 \mathrm{~cm}$.

Films of the chest in the respirator, one at $46 \mathrm{~cm}$. of water, negative pressure (inspiration), and the other at $39 \mathrm{~cm}$. of water, positive pressure (expiration) show a change of $10.5 \mathrm{~cm}$. in the height of the diaphragms and a much more marked change in the width of the chest. The latter cannot be measured, as at expiration the edges of the chest are beyond the limits of our largest film. It is estimated to be about $6 \mathrm{~cm}$. A comparison of the two sets of films shows that forced inspiration and expiration cause more change in aeration of the lungs than do voluntary inspiration and expiration.

THE APPARATUS USED AS A MEANS OF RECORDING RESPIRATORY MOVEMENTS

When the subject lies at rest in the respirator breathing naturally without the mechanical assistance of the pump, the expansion of the chest caused by inspiration raises the pressure of the air in the respirator and, conversely, the deflation of the chest caused by expiration lowers the pressure. If now a manometer of high sensitivity be connected to the respirator, the respiratory movements can be easily followed. The sensitivity of such a manometer may be greatly augmented by tilting it at an angle of 5 or 6 degrees with the horizontal and by using a liquid of low specific gravity, such as ether.

By treating our respirator as a body plethysmograph, the respiratory movements may be recorded volumetrically. This may be effected by connecting the respirator with a Krogh spirometer of 5 or 6 liters capacity, with a writing point in apposition with a kymograph. At inspiration, a volume of air equivalent to that inspired is displaced into the spirometer by the expansion of the chest and at expiration the air is again withdrawn from the spirometer by the contraction of the chest. The alternate movements of the spirometer lid writes a record both of respiratory movements and of respiratory volumes. The accuracy of the latter is directly proportional to the sensitivity of the spirometer and inversely proportional to the volume of air surrounding the body, since a certain slight pressure must be built up in the plethysmograph to overcome the inertia of the spirometer.

This method of recording respiration has been previously used by Shaw (1928) and also by Binger and Davis (1928). 
Since the tank can be changed at will from a mechanical respirator to a plethysmograph, it gives a convenient and clinically practical method of observing in pathologic cases whether the subject's normal breathing is being resumed.

\section{CONTROL OF TEMPERATURE AND HUMIDITY}

A thermostat for controlling the temperature and humidity of the air in the tank is screwed in at the foot end near the top. When the tank is completely shut-when the pumps are not running and no air is being introduced from outside- the patient's body heat raises the temperature within to an uncomfortable degree, if some sort of thermostatic mechanism is not provided. In our apparatus, the air within the tank is circulated through a can of ice, which serves both as a dehumidifier and a cooling agent. The small blower, producing the air circulation, is controlled by this thermostat.

When the pumps are running, the air is continually being changedthe air withdrawn from the tank is exhausted and blown into the room, without finding its way directly into the tank again. Then thermostatic control is not needed.

\section{DISCUSSION}

We recently had an opportunity to apply our respirator (1929) in a case of intercostal paralysis from poliomyelitis. The patient, a child of eight years, was in the machine almost continuously for a period of 122 hours, at the end of which time death occurred, resulting apparently from cardiac failure brought on by an extensive bronchopneumonia in the right lung. Examination of the lungs at autopsy showed no evidence of trauma from overinflation, nor was any other form of damage to the patient from this prolonged application of artificial respiration observed. During the time the child was in the respirator, she was able to talk, sleep, and take nourishment while the pumps were running.

This case and another described by Petrén and Sjövall (1926) indicate that respiratory failure in cases of poliomyelitis can be prevented and encourage the hope that recovery may follow in certain cases which would otherwise terminate fatally. 
Our respirator in its present form, like Thunberg's Barospirator, is a rather cumbersome and complicated apparatus - it is a clinical tool to be used in hospitals under the direction of competent clinicians. For emergency rescue work, it cannot displace the Schäfer method of manual resuscitation.

We are indebted to the gas and electric companies affiliated with the Consolidated Gas Company of New York through their Committee on Resuscitation and Related Activities for the funds which enabled us to bring this apparatus through the experimental stages.

We wish to express our thanks to Mr. F. C. Christensen, Superintendent of the Machine Shop of the Harvard Medical School, who designed and manufactured the valve mechanism of this apparatus. We are especially indebted to him for the many improvements which he has introduced since the first experimental respirator was built.

\section{SUMMARY}

The literature on mechanically operated devices for the application of artificial respiration is briefly reviewed and a new type of respirator is described and illustrated. This respirator consists in a metal tank, sealed at one end, in which the patient is placed, his head protruding through a rubber collar attached to the open end of the tank. By electrically operated pumps, the atmosphere within the tank is placed alternately under positive and negative pressure, positive pressure inducing expiration and negative pressure inspiration. The pressure changes per minute can be varied from 10 to 40 and any combination of pressures, positive or negative, from approximately $60 \mathrm{~cm}$. of water to atmospheric pressure can be obtained. The average threshold pressures - those which induce breathing against the subject's willare found to be about 5 to $10 \mathrm{~cm}$. of water for normal men and woman. Apnea can be produced by means of the respirator and an apneic subject can be made to breathe deeply.

By turning a valve at the foot end, the respiration tank is converted instantly into a plethysmograph. If a suitable spirometer is attached, graphic records of breathing can be made and the patient's ability to breathe without assistance determined. 


\section{BIBLIOGRAPHY}

Binger, C. A. L., and Davis, J. S., Jr., Proc. Soc. Exp. Biol. and Med., 1928, xxv, 607. A Body Plethysmograph for the Study of Respiratory Movements in Human Beings.

Doe, O. W., Boston Med. and Surg. J. 1889, cxx, 9. Apparatus for Resuscitating Asphyxiated Children.

Drinker, P., and McKhann, C. F., J.Am. Med. Assoc., 1929, xcii, 1658. The Use of a New Apparatus for the Prolonged Administration of Artificial Respiration.

I. A Fatal Case of Poliomyelitis. Drinker, P., Thomson, R. M., and Finn, J. L., J. Indust. Hyg., 1927, ix, 331. Metal Fume Fever: IV. Threshold Doses of Zinc Oxide, Preventive Measures, and the Chronic Effects of Repeated Exposures.

Eisenmenger, R., 1928. U. S. Patent No. 1,670,301.

Engineering Committee of the Conference on Electric Shock, J. Indust. Hyg., 1928, x, 117. Recent Experience of the Public Utilities of the United States and Canarla in the Use of the Schäfer Prone Pressure Method of Resuscitation in Cases of Electric Shock.

Keith, A., Lancet, $1909,1,745,825,895$. The Mechanism Underlying the Various Methods of Artificial Respiration.

Petrén, K., and Sjövall, E., Acta med. Scadinav., 1926, lxiv, 260. Eine Studie ïber die tödliche akute Form der Poliomyelitis.

Shaw, L. A., Am. J. Physiol., 1928, lxxxv, 158. Cutaneous Respiration of the Cat.

Steuart, W., Med. J. So. Africa, 1918, xiii, 147. Demonstration of Apparatus for Inducing Artificial Respiration for Long Periods.

Thunberg, T., Abderhalden's Handbuch der biologischen Arbeitsmethoden, 1927, Abt. 5, Teil 1, 561. Der Barospirator. Ein Apparat für künstliche Atmung nach einem neuen Prinzip. 